\title{
EVIDENTIAL REASONING-BASED AIRLINE NETWORK DESIGN FOR LONG-HAUL TRANSPORTATION IN EXPRESS DELIVERY
}

\author{
Fei Gao, Qilan Zhao
}

Preliminary communication

In express delivery, air couriers have been used extensively for transporting express freight due to its high efficiency and security, which are the most important considerations of the customers. The large volume of cargo forces the express company to build its own airline networks, aiming at improving the efficiency of delivery and reducing the transport cost. The conventional optimal solutions are very complex for use in designing networks with transferring hubs, and, in addition, the port conditions, including the volume of rainfall, the volume of railway transportation, average throughput, and hardware infrastructure, cannot be considered fully. In this paper, we formulate the express airline network design problem as an evidential reasoningbased evaluation process with multi-dimensional data. We used the Dempster-Shafer evidence theory to provide a flexible scheme to solve the evaluation task, and we proposed an evidential reasoning process specific for designing an express network to determine the best choice of the transferring hub. The proposed approach was applied in the design of the airline network for the ShunFeng express company, and the case study demonstrated that the proposed scheme can obtain a reasonable transport network with higher efficiency and lower cost.

Keywords: air freight; evidential reasoning; express transport; network design

\section{Planiranje mreže aerodroma za prijevoz na velike udaljenosti kod hitne isporuke zasnovano na evidentnom zaključivanju}

Prethodno priopćenje

Kod hitne isporuke, za ekspresni prijevoz robe uvelike se koristi avionska dostava zbog visoke učinkovitosti i sigurnosti, najvažnijih za kupce. Velika količina tereta prisiljava ekspresne kompanije na uspostavu vlastitih avionskih mreža u svrhu poboljšanja efikasnosti isporuke i snižavanja troškova prijevoza. Uobičajena optimalna rješenja imaju vrlo složeno dizajnirane mreže s čvorištima za prijelaz; štoviše, uvjeti, uključujući količinu oborina, volumen željezničkog prijevoza, prosječnu propusnost i infrastrukturu hardwera, ne mogu se u potpunosti uzeti u obzir. U ovom radu formuliramo problem dizajna ekspresne avionske mreže kao proces vrednovanja zasnovan na evidentnom zaključivanju s multidimenzijskim podacima. U svrhu osiguranja fleksibilne scheme za rješavanje zadatka procjenjivanja primijenjena je Dempster-Shafer teorija dokaza, a postupak evidentnog zaključivanja specifičan za dizajniranje ekspresnih mreža predlaže se kako bi se osigurao najbolji izbor čvorišta za prijelaz. Predloženi pristup je primijenjen kod projektiranja avionske mreže za ShunFeng ekspres kompaniju, a analiza tog slučaja pokazuje da se predloženom schemom može osigurati razumna transportna mreža uz više učinkovitosti i niže cijene.

Ključne riječi: dizajn mreže; ekspresni prijevoz; evidentno zaključivanje; pristojba za zračni prijevoz

\section{Introduction}

In recent years, the express delivery industry has grown rapidly. Although many express companies have emerged, such companies are still being formed at a rate that amounts to about a $40 \%$ increase in such companies every year [1]. Transportation Efficiency and security are the two most important considerations in the long-haul cargo delivery industry, and the best choice for ensuring these considerations is using the air carriers [2]. In the past, the air transportation of an express company was achieved by renting air freighters from the airlines, and the cargo was transported each time based on the real time requirements. However, this practice cannot handle the rapid growth in the volume of express cargo, and express companies have begun to establish their own air transportation networks in order to properly plan for and conduct the transportation of cargo. In addition, cost of transporting the cargo can be decreased by using their own air carriers.

Of course, considering the economic factors is the basic prerequisite when designing air transportation networks (ATNs). An efficient transportation line with too high cost is not viable in practical situations, e.g., when the number of customers is not sufficient to support a dedicated transportation line. In this paper, we report the results of our study of the problem of designing ATNs considering the three ways of transporting cargo described below.
Direct air lines. The best choice for two airports between which there is a sufficient exchange of cargo is to use direct airline transportation. There are two types of airlines, i.e., one-way airlines and round-trip airlines. The former is suitable for asymmetric transportation scenarios, and the latter is suitable for symmetric transportation scenarios. In general, the average cost of one-way transportation is higher than the cost for round-trip transportation. For example, the average weight of the daily cargo from Hangzhou to Weifang is 14 tons, but the daily weight from Weifang to Hangzhou is just 6 tons. In this situation, a one-way transportation airline is feasible from Hangzhou to Weifang, but it is not economically feasible to operate a one-way airline from Weifang to Hangzhou. Considering other routes, the total weights of cargo between Hangzhou and Shenzhen and between Shenzhen and Hangzhou are 58 and 64 tons, respectively. Thus, several round-trip lines would be feasible between Hangzhou and Shenzhen. Note that round-trip and oneway lines can exist simultaneously between two nodes because the weights of cargo still can be asymmetric even both are large.

Transferring air lines. For two airports that have an insufficient exchange of cargo, the use of direct lines is impractical due to its relative high cost. However, using roads or railways to haul cargo is still too slow to meet the efficiency requirement. In this scenario, using airlines to transfer the cargo is the best choice. First, the cargo can be transported to a transfer airport from several different 
cities. If the total weight is large enough, airlines can be opened in the transfer airport. This practice will inevitably increase the total volume of the transfer airport, which should be considered to avoid excessive volumes. Also, the cost for customers will be higher due to the increase in the cost for transportation.

Surface transportation. If the weight of the cargo is too small to support the use of air transportation, surface transportation will be used, including highways and railways haulage, even though they are not efficient enough.

Conventionally, optimization models are used to determine the optimal network topology, and there are many references to related work [3-6]. Some intelligent searching algorithms, such as the genetic algorithm in [7] and simulated annealing in [8], also have been used to design networks. However, the conventional optimal solutions mentioned above have are very complex to use for designing networks in which cargo must be transferred to hubs, and there is no way to accurately estimate the conditions of the ports, such as the volume of rainfall, the volume of railway transportation, the average throughput, and the hardware infrastructure. Therefore, other practical and flexible solutions must be identified to ensure that the express freight is handled expeditiously.

The Dempster-Shafer evidence theory (DSET) has been used extensively to solve evaluation, as indicated in [911]. DSET provides a flexible framework in which multiple index data can be combined without considering their dimensions. In our approach, the key point is to determine a suitable air freight hub to transfer the cargo. Since the network design problem in this paper involves complex transport cost, time, and conditions data, we used DSET to solve the evaluation task in order to determine the best choice of the transferring hub. Basically, the evaluation problem can be regarded as a data fusion problem in which several index data are combined into one unified evaluation result. Conventionally, an index is quantified with one set of data, and the evaluation methods are designed based on this one-dimensional scenario, such as the analysis process (AHP) in [12] and the technique for order preference by similarity to ideal solution (TOPSIS) in [13]. However, in practice, index data are not always represented with one scalar set of data, but it can be a vector, a matrix, or even complex structures. These multidimensional index data make the conventional evaluation methods unacceptable for dealing with this kind of problem, so we have to seek other theories to model this scenario. The detailed evidential reasoning process, including the construction of basic belief assignment (BBA), weight assignment, and combination are illustrated. A case study on the design of an air freight network is provided for the ShunFeng (SF) company.

The remainder of this paper is organized as follows: Section 2 introduces the preliminaries of DSET and Saaty's rating scale, and the proposed method for the design of an evidential reasoning-based network is presented in Section 3, which includes the process of establishing an index system, the construction of BBA, the assignment of weights, and the combination of BBA. The results are provided in Section 4, and our conclusions are presented in Section 5.

\section{Preliminaries}

In this section, we illustrate the general model using the belief function theory for evaluation with hierarchy structure. The preliminaries of belief function theory also are introduced. Particularly, the advantage in handling multi-dimensional index data is highlighted.

Fig. 1 shows our analysis hierarchy process with multi-dimensional data. In the operating hierarchy, there are $\Omega=\left\{\omega_{1}, \ldots, \omega_{c}\right\}$ possible candidates. Accordingly, each index has $c$ data to evaluate. The indices used as the basis of the evaluation are denoted as $V=\left\{v_{1}, \ldots, v_{n}\right\}$, and their corresponding weights are $\Gamma=\left\{\gamma_{1}, \ldots, \gamma_{n}\right\}$, which will be obtained by using Saaty's rating scale matrix, which is presented in the next subsection.

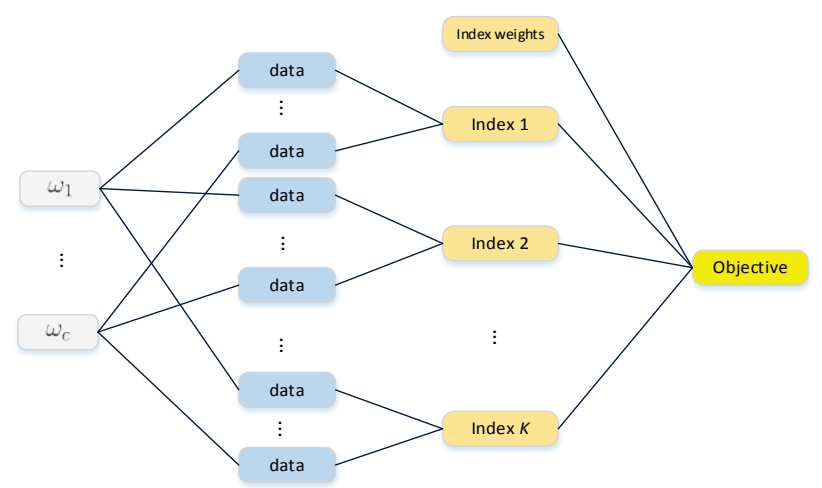

Figure 1 Analysis hierarchy with multi-dimensional data

\subsection{Basics of DSET}

The Dempster-Shafer evidence theory (DSET), also known as the belief function theory, initially was proposed by Dempster [14], and, later, it was justified by Shafer in 1976 [15]. DSET provides a flexible uncertainty reasoning framework for dealing with the problem of fusing multi-source data. In DSET, the frame of discernment is a non-empty set composed of mutually exclusive and exhaustive elements, and this frame is denoted as $\Omega=\left\{\omega_{1}, \ldots, \omega_{c}\right\}$. Let $2^{\Omega}$ be the power set of $\Omega$, given a mass function $m$ i.e. $2^{\Omega} \rightarrow[0,1]$, and $m$ holds

$\sum_{A \in 2^{\Omega}} m(A)=1$, and $m(\phi)=0$.

Function $m$ is referred to as the basic belief assignment (BBA) to the frame of discernment, $\Omega$. It is important to emphasize that the key point when using DSET to solve evaluation problems is constructing reasonable BBAs. A good mass function improves the reliability of the results of the evaluation. Also, the computational complexity is reduced, so the process of constructing the BBA should be considered carefully.

For compound set, $\Omega$, its BBA $m(\Omega)$ represents the uncertainty of all hypotheses in the discernment of the framework. For a subsect $A \in \Omega$, pattern $\{A \mid m(A)\}$ is called a piece of evidence, and if $m(A) \neq 0,\{A \mid m(A)\}$ is also called a focal element. In DSET, the degrees of support are obtained by two dual measurements, i.e., the belief function, $\operatorname{Bel}(A)$, and the plausibility function, $\operatorname{Pls}(A)$, where the former function is equal to the total BBAs of the subsets that support hypothesis $A$, and the 
latter function is equal to the total BBAs of the subsets that do not reject hypothesis $A$. Therefore, we have

$$
\begin{aligned}
& \operatorname{Bel}(A)=\sum_{B \in A} m(B), \\
& P l s(A)=\sum_{A \cap B \neq 0} m(B) .
\end{aligned}
$$

$\operatorname{Bel}(A)$ and $P l s(A)$ can be regarded as the lower bound and upper bound, respectively, of the support degree of hypothesis $A$. Apparently, the dual measurements hold the following two relationships

$$
\begin{aligned}
& \operatorname{Pls}(A)=1-\operatorname{Bel}(\bar{A}), \\
& \operatorname{Pls}(A) \geq \operatorname{Bel}(A) .
\end{aligned}
$$

DSET can deal with the multi-index evaluation problem because of its ability to combine several independent BBAs into a unified BBA. Given $n$ BBAs, $m_{1}, \ldots, m_{n}$, that are assumed to be mutually independent, for $\forall A \subseteq \Omega$ and $\mathrm{A} \neq \phi$, the Dempster's combinational rule is defined as

$$
m(A)=\frac{\sum_{\cap A_{j}=A} \prod_{i=1}^{n} m_{i}\left(A_{j}\right)}{1-k}
$$

where $k$ is the degree of conflict among the $n$ BBAs, and it is calculated by

$$
k=\sum_{\cap A_{j}=\phi} \prod_{i=1}^{n} m_{i}\left(A_{j}\right)
$$

Also, $k$ can be regarded as merely a normalization factor. When the value of $k$ is close to 1 , the $n$ BBAs are not suitable to be directly combined, and this should have been avoided in the BBA construction process. The weighting operation in DSET is referred to as the "discounting operation". When an index cannot be fully trusted, a parameter called reliability, $t \in[0,1]$, can be used. In this paper, we still designate the weight as $t$, and the discounting operation is defined by

$$
\begin{aligned}
& m^{\prime}(A)=t m(A), \\
& m^{\prime}(\Omega)=1-t+t m(\Omega) .
\end{aligned}
$$

When $t=0$, the corresponding index is totally unreliable for evaluation, and it should not be considered. However, if $t=1$, the corresponding index is very important, and we must make full use of it. The reasonableness of the discounting operation relies on the weight, so the weight-assignment algorithm is very important. In this paper, we used Saaty's [16] rating scale matrix to calculate the index weights in the next subsection.

\subsection{Saaty's rating scale}

The importance of the indices is not same, so they should be assigned different weights in the combination process. Saaty suggested that a solution would be to construct a pair-wise rating scale matrix to obtain the index weights [17]. We defined $a_{i, j}$ as the ratio of the degrees of importance $\mathrm{f}$ indices $v_{i}$ and $v_{j}$, and the scale is defined as shown in Tab. 1.

The pair-wise rating scale matrix $\boldsymbol{A}=\left[a_{i, j}\right]_{n \times n}$ can be used to obtain the importance of the degrees of the indices by calculating the eigenvectors. However, before the process of calculating the weights, we must check the consistency of the rating scale matrix. The consistency index is defined as

$C I=\frac{\lambda_{\max }-n}{n-1}$

where $\lambda_{\max }$ is the maximum eigenvalue of the rating scale matrix, and $n$ is the number of indices. The average random consistency index $(R I)$ when $1 \leq n \leq 9$ is given in Tab. 2. The consistency ratio, $C R$, can be obtained by

$C R=\frac{C I}{R I}$

When $C R<0.1$, the rating scale matrix is reasonable and it can be accepted; otherwise, it is unreasonable, and we have to refine it. Last, the weights of the indices can be obtained according to the eigenvector with maximum eigenvalue, $\lambda_{\max }$.

Table 1 Saaty's rating scale

\begin{tabular}{|c|l|}
\hline Scale & \multicolumn{1}{c|}{ Definition } \\
\hline 1 & The same importance \\
\hline 3 & Somewhat more important \\
\hline 5 & Absolutely more important \\
\hline 7 & Strongly more important \\
\hline 9 & Extremely more important \\
\hline $2,4,6,8$ & Intermediate values \\
\hline
\end{tabular}

Table $2 R I$ values

\begin{tabular}{|c|c|c|c|c|c|c|c|c|c|}
\hline$n$ & 1 & 2 & 3 & 4 & 5 & 6 & 7 & 8 & 9 \\
\hline$R I$ & 0 & 0 & 0.58 & 0.9 & 1.12 & 1.24 & 1.32 & 1.41 & 1.45 \\
\hline
\end{tabular}

\section{Evaluation using hierarchal evidential reasoning 3.1 Problem formulation}

We consider a site selection problem with $N$ airports and $K$ candidate air transport hubs, which are denoted as $A=\left\{a_{1}, \ldots, a_{N}\right\}$ and $\Omega=\left\{\omega_{1}, \ldots, \omega_{k}\right\}$, respectively. Note that $\Omega \in A$, i.e., the candidate hubs are also airports for the transportation of cargo. We denote $x_{i, j}$ and $t_{i, j}$ as the volume of transported cargo and the transport time, respectively, from $a_{i}$ to $a_{j}$, and the network is designed based on the following principles:

If $x_{i, j}>x_{t h}$, i.e., the volume of cargo $x_{i, j}$ from $a_{i}$ to $a_{j}$ is larger than the threshold $x_{t h}$, then use a direct line to transport the cargo.

$$
\text { If } x_{i, j}<x_{t h} \text { and } \frac{t_{i, k}+t_{k, j}}{t_{i, j}} \leq r_{t h} \text {, where } a_{k} \text { is the }
$$

transferring hub, and the volume and time ratios are both lower than the threshold, then choose the transfer hub to transport the cargo. 
If neither of the two conditions is satisfied, use surface transportation. Usually, railway transportation is used for long-haul transportation.

\subsection{Indices}

With the above design principles, the key point is to determine the optimal solution to select a transfer hub for the network. In this paper, we used the DSET to find the hub, not conventional optimization models. We did so because, in the express business, both the cost and efficiency of transport are important. Also, the conditions of candidate ports should be considered. To determine the best choice of a hub, first, we set the evaluation indices as described below.

Conditions of candidate ports. The following four indices are used to reflect the condition of an airport, i.e., the index of the volume of rainfall, $v_{1}$, the index of the volume of railway transportation, $v_{2}$, the index of average throughput, $v_{3}$, and the index of the hardware infrastructure, $v_{4}$. The volume of rainfall is used because air transport is heavily influenced by rain, and this index is obtained by calculating the average volume of rainfall; the index data are given in Tab. 3 .

The railway transportation index is the total number of trains that provide railway transportation to the city. The average throughput index directly represents the capacity of the airport. The hardware installations are quantified by using the total surface area of terminal buildings, which indicates the storage capacity of the airport.

Transport efficiency index $v_{\mathbf{5}}$, which is quantified by the flying hours between the ports, and the times among the ports are shown in Tab. 5. As mentioned earlier, time efficiency is one of the most important considerations in express delivery, thus it must be an evaluation index.

The transport cost index $v_{6}$, is equal to the sum of the in-port cost and the out-port cost. For $a_{i}$ and $a_{k}$, the total transport cost between the two ports can be calculated from Eq. (9):

$c_{i, k}=c_{0} t_{i, k}\left(x_{i, k}+x_{k, i}\right)$,

where $c_{0}$ is the unit cost of one $\mathrm{kg}$ of cargo. In this paper, we assumed that $c_{0}$ is a constant value. Tab. 4 shows the cargo of all of the ports.

The data of the former four indices, i.e., $v_{1}, \ldots, v_{4}$ are vectors, but the index data of $v_{5}$ and $v_{6}$ are matrices. To fully utilize the multi-dimensional index data, we used the DSET-based evaluation to model the evaluation task. Fig. 2 shows that, first, the original index data will be transferred to basic belief assignments (BBAs) by using a BBA construction algorithm. We use the simple support BBA construction process to calculate the BBAs of the indices. Subsequently, the weight assignment-based Saaty's rule is used to discount the index BBAs that were obtained. Next the weighted index BBAs are combined to obtain the quality BBAs, which include the BBA of the quality of the transport line and the BBA of the condition of the port. The global BBA is obtained by combining the two quality BBAs mentioned above. In the proposed approach, Dempster's combinational rule is used to merge the BBAs.

Table 3 Index data of the conditions of the candidate hubs

\begin{tabular}{|l|c|c|c|c|c|}
\hline \multicolumn{1}{|c|}{ Index } & Chongqing & Wuhan & Chengdu & Xian & Changsha \\
\hline Approximate rainfall (mm/year) & 1452 & 1209 & 975 & 659 \\
\hline Throughput $\left(10^{4}\right.$ persons/year) & 3239 & 1894 & 4200 & 3269 \\
\hline Infrastructure area $\left(10^{4} \mathrm{~m}^{2}\right)$ & 70 & 51 & 47 & 367 \\
\hline Railway lines & 220 & 616 & 343 & 21.2 & \\
\hline
\end{tabular}

Table 4 Volumes of the cargo transported between the ports (tons)

\begin{tabular}{|c|c|c|c|c|c|c|c|c|c|c|c|c|c|c|c|c|c|c|}
\hline & Beijing & Shanghai & Chongqing & Shenyang & Whanan & Chengdu & Xian & Thengzhou & Fuxi & Woifang & Hangzhou & Fuzhou & Changsha & Shenzher & Thunyi & Nujiang & Orunqi & Total \\
\hline Beijing & 0 & 13585 & 2339 & 9219 & 3541 & 4825 & 3418 & 3483 & 11433 & 11911 & 11978 & 4923 & 2143 & 21460 & 1799 & 1521 & 3986 & 111566 \\
\hline Shanghai & 20425 & 0 & 1974 & 6909 & 3106 & 3810 & 2253 & 2416 & 0 & 8803 & 0 & 0 & 2157 & 21265 & 5780 & 2216 & 2045 & 83160 \\
\hline Chongqing & 750 & 589 & 0 & 338 & 354 & 0 & 188 & 173 & 459 & 273 & 598 & 308 & 115 & 1766 & 53 & 92 & 360 & 6416 \\
\hline Shenyang & 6190 & 3073 & 519 & 0 & 600 & 839 & 425 & 513 & 2070 & 2207 & 2997 & 657 & 364 & 4188 & 735 & 204 & 529 & 26112 \\
\hline Wuhan & 2822 & 1827 & 520 & 464 & 0 & 1010 & 407 & 565 & 1468 & 825 & 1930 & 989 & 0 & 5029 & 375 & 246 & 456 & 18934 \\
\hline Chengdu & 3036 & 1059 & 0 & 604 & 662 & 0 & 474 & 462 & 1281 & 1057 & 1416 & 654 & 557 & 3628 & 157 & 214 & 565 & 15825 \\
\hline Xian & 1760 & 815 & 140 & 382 & 266 & 454 & 0 & 316 & 952 & 396 & 714 & 338 & 159 & 1789 & 133 & 94 & 467 & 9175 \\
\hline Thengzhou & 1726 & 1106 & 290 & 465 & 536 & 445 & 310 & 0 & 1029 & 641 & 1311 & 719 & 248 & 2685 & 204 & 128 & 271 & 12114 \\
\hline Wwoxi & 16331 & 0 & 1697 & 5880 & 3129 & 4807 & 2364 & 2711 & 0 & 8247 & 0 & 0 & 1783 & 33784 & 8294 & 2579 & 1465 & 93072 \\
\hline Weifang & 9092 & 6419 & 784 & 2533 & 890 & 1699 & 797 & 959 & 5006 & 0 & 5672 & 1996 & 954 & 12446 & 2829 & 1024 & 685 & 53783 \\
\hline Hangzhou & 23857 & 0 & 4524 & 9332 & 4366 & 9145 & 4773 & 4088 & 0 & 13788 & 0 & 0 & 2764 & 58370 & 18852 & 5152 & 3636 & 162647 \\
\hline Fuzhou & 7525 & 0 & 693 & 1894 & 1480 & 1922 & 855 & 1367 & 0 & 2956 & 0 & 0 & 1054 & 0 & 5715 & 3562 & 1038 & 30062 \\
\hline Changsha & 1470 & 799 & 144 & 265 & 0 & 628 & 171 & 221 & 686 & 706 & 1105 & 478 & 0 & 3884 & 626 & 122 & 178 & 11483 \\
\hline \begin{tabular}{|l|} 
Shenzhen \\
\end{tabular} & 53138 & 44075 & 6925 & 14984 & 11754 & 13746 & 5754 & 9673 & 48691 & 24409 & 63753 & 0 & 9992 & 0 & 0 & 25011 & 8160 & 340063 \\
\hline Zhunyi & 2309 & 6347 & 142 & 858 & 215 & 210 & 31 & 115 & 6422 & 2125 & 9601 & 2675 & 140 & 0 & 0 & 3066 & 52 & 34350 \\
\hline Nujiang & 1047 & 1423 & 54 & 339 & 160 & 40 & 29 & 25 & 1976 & 743 & 2527 & 2423 & 33 & 12033 & 4154 & 0 & 3 & 27008 \\
\hline Uxumqi & 895 & 294 & 84 & 146 & 122 & 243 & 208 & 75 & 216 & 184 & 509 & 198 & 64 & 1164 & 16 & 10 & 0 & 4430 \\
\hline Total & 152372 & 81412 & 20830 & 54613 & 31181 & 43825 & 22496 & 27159 & 81690 & 79271 & 104112 & 16359 & 22526 & 183493 & 49724 & 45242 & 23896 & 1040202 \\
\hline
\end{tabular}


Table 5 Transportation times between the ports (hours)

\begin{tabular}{|c|c|c|c|c|c|c|c|c|c|c|c|c|c|c|c|c|c|}
\hline & Beijing & Shanghai & Chongqing & Shenyang & Wuhan & Chengdu & Xian & Zhengzhou & Wuri & Weifang & Hangzhou & Furhou & Changsha & Shenzhen & Zhunyi & Nüüang & Unumqi \\
\hline Beïing & 0 & 2.1 & 3.1 & 3 & 2.5 & 3.2 & 22 & 1.5 & 2.4 & 2 & 2.5 & 2.4 & 2.5 & 3 & 3 & 3 & 5.5 \\
\hline Shanghai & 2.1 & 0 & 3 & 25 & 2 & 3.4 & 2.8 & 2 & 0 & 2.4 & 0 & 0 & 2 & 2.5 & 3 & 32 & 6 \\
\hline Chongqing & 3.1 & 3 & 0 & 4 & 1.5 & 0 & 1.5 & 1.8 & 2.2 & 2.7 & 2.3 & 2.5 & 1.5 & 2 & 1.5 & 25 & 4 \\
\hline \begin{tabular}{|l|} 
Shenyang \\
\end{tabular} & 3 & 2.5 & 4 & 0 & 3.5 & 4.5 & 4 & 2.7 & 2.5 & 1.6 & 2.5 & 4.5 & 4.5 & 5 & 5 & 5.5 & 6 \\
\hline Wuhan & 2.5 & 2 & 1.5 & 3.5 & 0 & 2 & 1.5 & 1.5 & 1.5 & 2 & 1.5 & 1.5 & 0 & 1.7 & 1.5 & 2.5 & 4 \\
\hline Chengdu & 3.2 & 3.4 & 0 & 4.5 & 2 & 0 & 1.5 & 2 & 2.5 & 3 & 2.7 & 3 & 2 & 2.5 & 2 & 2 & 4 \\
\hline Xian & 2.2 & 2.8 & 1.5 & 4 & 1.5 & 1.5 & 0 & 2.5 & 23 & 2.5 & 23 & 2.5 & 2 & 3 & 3 & 3 & 4 \\
\hline Zhengzhou & 1.5 & 2 & 1.8 & 2.7 & 1.5 & 2 & 25 & 0 & 15 & 1 & 1.5 & 2.5 & 2 & 2.5 & 3 & 3 & 6 \\
\hline Wwi & 2.4 & 0 & 2.2 & 25 & 1.5 & 2.5 & 23 & 1.5 & 0 & 1.5 & 0 & 0 & 1.7 & 2.8 & 3 & 35 & 7 \\
\hline Weifang & 2 & 2.4 & 2.7 & 1.6 & 2 & 3 & 2.5 & 1 & 1.5 & 0 & 3 & 4 & 2.5 & 4 & 4.5 & 4.5 & 7 \\
\hline \begin{tabular}{|l|} 
Hangzhou \\
\end{tabular} & 2.5 & 0 & 2.3 & 2.5 & 1.5 & 2.7 & 2.3 & 1.5 & 0 & 3 & 0 & 1.5 & 1.7 & 2.7 & 3 & 5 & 7 \\
\hline Furhou & 2.4 & 0 & 2.5 & 4.5 & 1.5 & 3 & 2.5 & 2.5 & 0 & 4 & 1.5 & 0 & 1.7 & 0 & 2.5 & 2.5 & 6.5 \\
\hline Changsha & 2.5 & 2 & 1.5 & 4.5 & 0 & 2 & 2 & 2 & 1.7 & 2.5 & 1.7 & 1.7 & 0 & 1.5 & 2 & 2 & 5 \\
\hline Shenzhen & 3 & 2.5 & 2 & 5 & 1.7 & 2.5 & 3 & 2.5 & 2.8 & 4 & 2.7 & 0 & 1.5 & 0 & 2 & 2 & 6.5 \\
\hline Zhunyi & 3 & 3 & 1.5 & 5 & 1.5 & 2 & 3 & 3 & 3 & 4.5 & 3 & 2.5 & 2 & 2 & 0 & 1.5 & 6 \\
\hline Nujiang & 3 & 32 & 2.5 & 5.5 & 2.5 & 2 & 3 & 3 & 3.5 & 4.5 & 5 & 2.5 & 2 & 2 & 1.5 & 0 & 7 \\
\hline Urumqi & 4.5 & 6 & 4 & 6 & 4 & 4 & 4 & 6 & 7 & 7 & 7 & 6.5 & 5 & 6.5 & 6 & 7 & 0 \\
\hline
\end{tabular}

\subsection{BBA construction}

In this subsection, we show how to transfer the index data into bbas. The cost and hours required for transport between $a_{i}$ and $\omega_{j}$ are designated as $c_{i, j}$ and $d_{i, j}$, respectively. In turn, the four condition indices, i.e., volume of surface transportation, rainfall, average throughput, and hardware installations, are denoted as $v_{1}$, $v_{2}, v_{3}$, and $v_{4}$, respectively. The $i^{\text {th }}$ condition data of $\omega_{j}$ is denoted as $d_{i, j}$. Note that, if airport $a_{i}$ and candidate air hub $\omega_{j}$ are the same, we have $c_{i, j}=0$ and $t_{i, j}=0$.

First, we introduce the BBA construction of the four condition indices. For index $v_{i}(1 \leq i \leq 4)$, a larger index data indicates higher possibility of the candidate, e.g., $v_{2}$ (throughput), the corresponding membership degree of class $\omega_{j}$ is calculated by using the following exponential transferring function

$\mu_{i, j}=\alpha e^{-\beta\left(\frac{d_{i, j}}{\bar{d}_{j}}\right)^{2}}$,

where $\alpha$ and $\beta$ are two constant parameters to adjust the obtained membership. Usually, $\alpha$ is set close to 1 , such as 0.95. The term $\bar{c}_{j}$ is the mean value of the index data of candidate $\omega_{j}$, i.e., $\bar{d}_{j}=\frac{1}{N} \sum_{i=1}^{N} d_{i, j}$. When a larger amount of index data indicates a lower possibility of the candidate, e.g., $v_{1}$ (rainfall), the membership function is obtained as

$\mu_{i, j}=1-\alpha e^{-\beta\left(\frac{d_{i, j}}{\bar{d}_{j}}\right)^{2}}$.

Subsequently, we obtain the simple support BBAs from

$m_{i, j}^{s}\left(\omega_{j}\right)=\mu_{i, j}$,

$m_{i, j}^{s}\left(\omega_{k}\right)=0, \forall \omega_{k} \in 2^{\Omega} \mid\left\{\omega_{j}, \Omega\right\}$,
The index BBA to $a_{i}$ can be calculated by combining the $c$ simple support BBAs, as in Eq. (13):

$m_{i}=m_{i, 1}^{s} \oplus m_{i, 2}^{s} \oplus \cdots \oplus m_{i, c}^{s}$,

where $\oplus$ designates Dempster's combination operation. The explicit form of $m_{i}^{c}$ is given by

$$
\begin{aligned}
& m_{i}\left(\omega_{j}\right)=\frac{\mu_{i, j}}{1-k} \prod_{k=1, k \neq j}^{c}\left(1-\mu_{i, k}\right), \\
& m_{i}(\Omega)=\frac{1}{1-k} \prod_{k=1}^{c}\left(1-\mu_{i, k}\right),
\end{aligned}
$$

where $k$ is the degree of conflict, or it can be regarded as the normalization parameter. BBA $m_{i}^{c}$ reflects the extent to which each candidate port is supported to be a transport hub. Next, we consider BBA construction of the indices for transport cost and transport time. There are 17 ports, and every index has the data from these ports. Therefore, the index data of cost and time are two $17 \times 5$ matrices. For $a_{i}$, suppose its cost to the five candidates are $c_{i, 1}, \ldots$, $c_{i, 5}$; then, by using Eq. (10), we can obtain 5 membership degrees, i.e., $\mu_{5,1}^{i}, \ldots, \mu_{5,5}^{i}$. In the same way, with Eqs. (14) and (16), we can obtain the BBA of port $a_{k}$, as given by

$$
\begin{aligned}
& m_{5}^{i}\left(\omega_{j}\right)=\frac{\mu_{5, j}^{i}}{1-k} \prod_{k=1, k \neq j}^{c}\left(1-\mu_{5, k}^{i}\right), \\
& m_{5}^{i}(\Omega)=\frac{1}{1-k} \prod_{k=1}^{c}\left(1-\mu_{5, j}^{i}\right), \\
& m_{5}=m_{5}^{1} \oplus m_{5}^{2} \oplus \cdots \oplus m_{5}^{N} .
\end{aligned}
$$

According to $[18,19]$, the explicit form of the combined BBA $m^{c}$ still can be obtained, as given by 


$$
\begin{aligned}
& m_{5}\left(\omega_{j}\right)=\frac{1}{1-k}\left[\prod_{i=1}^{N}\left(1-\mu_{5, j}\right)^{-1}-1\right] \prod_{i=1}^{N} m_{5}^{i}(\Omega), \\
& m_{5}(\Omega)=\frac{1}{1-k} \prod_{i=1}^{N} m_{5}^{i}(\Omega) .
\end{aligned}
$$

Table 6 Pair-wise rating scale matrix

\begin{tabular}{|l|c|c|c|c|c|c|}
\hline \multicolumn{1}{|c|}{ Index } & Rainfall & Throughput & Infrastructure & Railway & Time & Cost \\
\hline Rainfall & 1 & $1 / 5$ & $1 / 2$ & $1 / 3$ & $1 / 7$ & $1 / 6$ \\
\hline Throughput & 5 & 1 & 3 & 2 & $1 / 2$ & $1 / 2$ \\
\hline Infrastructure & 2 & $1 / 3$ & 1 & $1 / 2$ & $1 / 3$ & $1 / 3$ \\
\hline Railway & 3 & $1 / 2$ & 2 & 1 & $1 / 3$ & $1 / 2$ \\
\hline Time & 7 & 2 & 3 & 3 & 1 & 2 \\
\hline Cost & 5 & 2 & 3 & 2 & $1 / 2$ & 1 \\
\hline
\end{tabular}

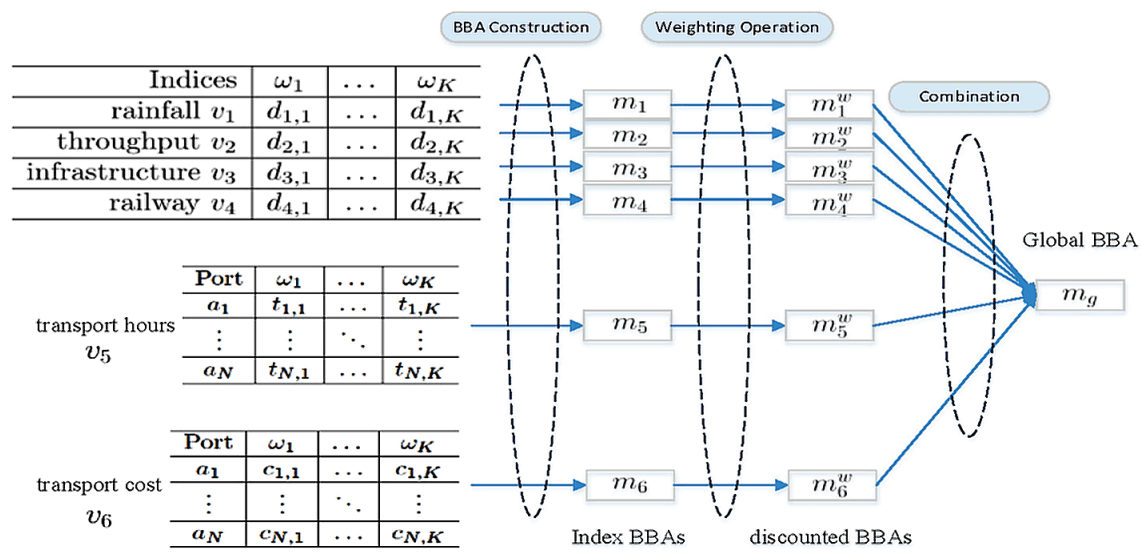

Figure 2 Flowchart of the evaluation process using evidential reasoning

\subsection{Weight assignment}

In preceding section, we illustrated the process of calculating the BBAs of transport cost, transport hours, and port conditions. However, we did not consider the discourse power of the indices. Generally speaking, a more important index should be assigned with a larger weight, therefore it would have a greater influence on the final combined BBAs. We used Saaty's rating scale to quantify the relative degrees of importance of the condition indices, as defined in Tab. 1. Note that the degrees of importance of the two indices are relative, thus the reciprocals of the rating can be regarded as the inverse of the above degrees. The rating scale matrix of the six indices is shown in Tab. 6.

In Tab. 6, time efficiency is the most important index because it is the primary concern of the customers. Cost is the second-most important index, since it is the primary concern of the express company. Throughput is the most important condition index because it reflects the transportation capacity and the efficiency of an airport.

Next, we check the consistency of the rating scale matrix. The maximum eigenvalue of the rating scale matrix is $\lambda_{\max }=6.0885$, thus we know that the consistency index is $C I=0.0177$ and that the consistency ratio $C R=$ 0.0143 , which is far smaller than 0.1 . Therefore, the rating scale matrix is reasonable, and we can use it to calculate the index weights. The corresponding eigenvector is obtained as $\lambda=[0.0838,0.3938,0.1621,0.2473,0.7078$, $0.4995]$. We define the weights of the six indices as $\gamma=$ $\left[\gamma_{1}, \ldots, \gamma_{6}\right]$, and they are calculated by:

$\gamma_{i}=\frac{\lambda_{i}}{\max \left\{\lambda_{1}, \ldots, \lambda_{6}\right\}+0,1}$.
In the same way, we can obtain the index BBAs of transport hours, $m_{6}$. With the obtained $m_{1}, \ldots, m_{6}$, the following weighting and combination operations can be conducted. 


$$
d_{g}=\arg \max _{1 \leq j \leq c}\left\{m\left(\omega_{j}\right)+\frac{1}{|\Omega|} m(\Omega)\right\},
$$

where $|\Omega|$ denotes the cardinality of $\Omega$. In this paper, we have 6 indices, so $|\Omega|=6$. With the selected transfer hub, the whole airline transport can be obtained.

\section{Results}

In this section, we apply the proposed model in the design of the backbone air transport lines of SF Express Company. SF Company is one of the largest express companies in China. The air transport business is about $40 \%$ of its total revenue, and it is growing rapidly, at a pace of about $40 \%$ per year, so it is essential that the Company build its own hub to transfer cargo.

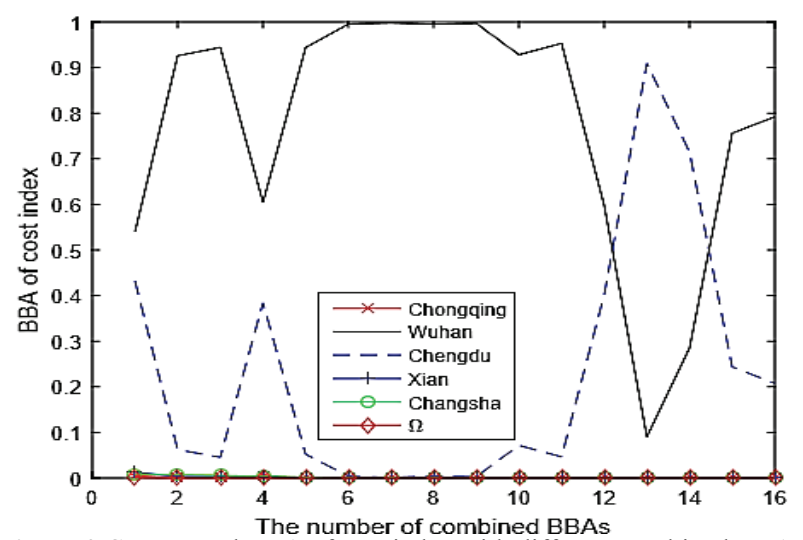

Figure 3 Constructed BBA of cost index with different combined BBAs

First, we show the process used to construct the BBAs of cost and time indices in the evidential reasoning, as depicted in Figs. 3 and 4. The BBAs that were obtained were constructed by combining the port BBAs in turn, from port 1 to port 17. For example, when the number of combined BBAs is 10 , it means that $m_{5}=m_{5}^{1} \oplus \cdots \oplus m_{5}^{10}$ and $m_{6}=m_{6}^{1} \oplus \cdots \oplus m_{6}^{10}$. We can observe that, for the cost index, the main possible hubs are Wuhan and Chengdu. For the time index, Wuhan City is still the most suitable city to be the transfer hub, but the result is convergent only when the number of combined BBAs is larger than 12. We can see that, when using DSET to solve evaluation problems, the obtained index BBAs will converge if the index data are sufficient, even though the index data are multi-dimensional.

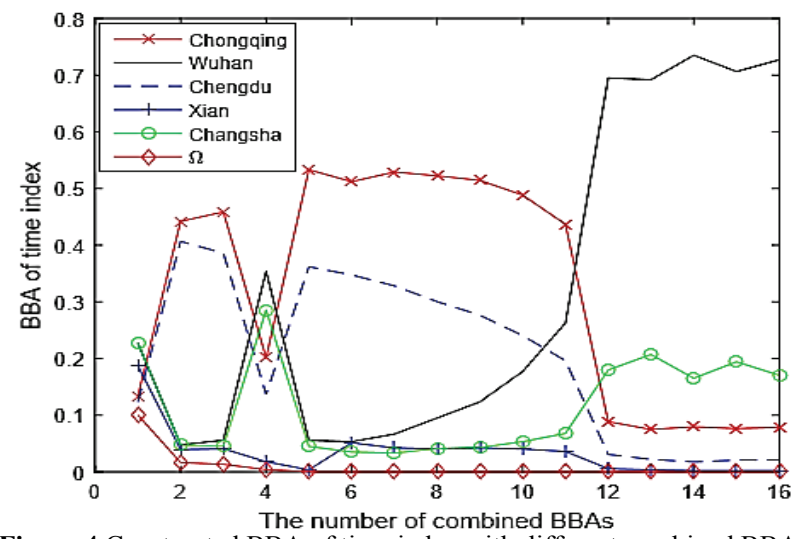

Figure 4 Constructed BBA of time index with different combined BBAs

Next, we show the obtained index BBAs and the corresponding discounted BBAs in Tabs. 7 and 8, respectively. We can see that Xian port has the best weather conditions and that Chengdu airport has the highest throughput, which means it has the best transferring capacity among the five candidates. The BBA of infrastructure of Chongqing airport is the largest, thus it has better hardware than its competitors. However, the Wuhan airport has better conditions in terms of railway transportation, transport cost, and transport time, which indicate it is the most appropriate airport to serve as a transfer hub. Able 8 shows that the discounted BBAs differ greatly from their undiscounted versions. When an index has lower weight, its singleton classes will be assigned much smaller BBAs, but the compound class $\Omega$ will be assigned with a much larger BBA, e.g., $m_{1}^{\omega}, m_{3}^{\omega}, m_{4}^{\omega}$. The reason is that, when the weight is small, the corresponding index will be regarded as unreliable to support the results, thus the BBA of the compound class will be larger to show the degree of ignorance of the index. In this way, the DSET method is flexible in representing the uncertainty of the index data.

Table 7 Constructed BBAs of the six indices

\begin{tabular}{|l|c|c|c|c|c|c|}
\hline \multicolumn{1}{|c|}{ Index } & Chongqing & Wuhan & Chengdu & Xian & Changsha & \multicolumn{1}{c|}{$\Omega$} \\
\hline$m_{1}$ (rainfall) & 0.0277 & 0.0655 & 0.1427 & 0.4138 & 0.0352 \\
\hline$m_{2}$ (throughput) & 0.1519 & 0.0258 & 0.6135 & 0.1582 & 0.0249 \\
\hline$m_{3}$ (infrastructure) & 0.7357 & 0.1188 & 0.0841 & 0.0334 & 0.009 \\
\hline$m_{4}$ (railway) & 0.0107 & 0.8115 & 0.0374 & 0.0151 & 0.1113 & 0.0191 \\
\hline$m_{5}$ (cost) & 0 & 0.7923 & 0.2077 & 0 & 0 \\
\hline$m_{6}$ (time) & 0.0787 & 0.7272 & 0.0213 & 0.0022 & 0.1706 & 0 \\
\hline
\end{tabular}

The global BBA that is obtained is $m_{g}=[0.0213$, $0.7862,0.1287,0.0089,0.0151,0.0399]$. We can conclude that Wuhan is the most appropriate port to be an air hub. Finally, we can obtain the designed airline transport network, as depicted in Fig. 5, in which the red lines designate the direct transport lines between two ports, and the blue lines denote the transfer lines between the hub (Wuhan) and the other ports. As mentioned earlier, the volume of the transported cargo increases by
$40 \%$ every year, thus it is important to note that the designed network should be adjusted with the growth of the business of the express company to meet the real time requirement without remaining static. For example, the volume of cargo from Wuxi to Beijing was 16 tons in 2015, and we may add a new line between the two ports if the weight exceeds 18 tons, since the transport air carriers are more efficient and economical compared with consignment. 
Table 8 Discounted BBAs of the six indices

\begin{tabular}{|l|c|c|c|c|c|c|}
\hline \multicolumn{1}{|c|}{ Index } & Chongqing & Wuhan & Chengdu & Xian & Changsha & $\Omega$ \\
\hline$m_{1}^{\omega}$ (rainfall) & 0.0029 & 0.0068 & 0.0148 & 0.0434 & 0.0036 & 0.9285 \\
\hline$m_{2}^{\omega}$ (throughput) & 0.074 & 0.0126 & 0.2991 & 0.0771 & 0.0121 & 0.5251 \\
\hline$m_{3}^{\omega}$ (infrastructure) & 0.1477 & 0.0238 & 0.0169 & 0.0067 & 0.0018 & 0.8031 \\
\hline$m_{4}^{\omega}$ (railway) & 0.0033 & 0.2484 & 0.0115 & 0.0046 & 0.0341 & 0.6982 \\
\hline$m_{5}^{\omega}$ (cost) & 0 & 0.6942 & 0.182 & 0 & 0 & 0.1238 \\
\hline$m_{6}^{\omega}$ (time) & 0.0487 & 0.4497 & 0.0132 & 0.0013 & 0.1055 & 0.3817 \\
\hline
\end{tabular}

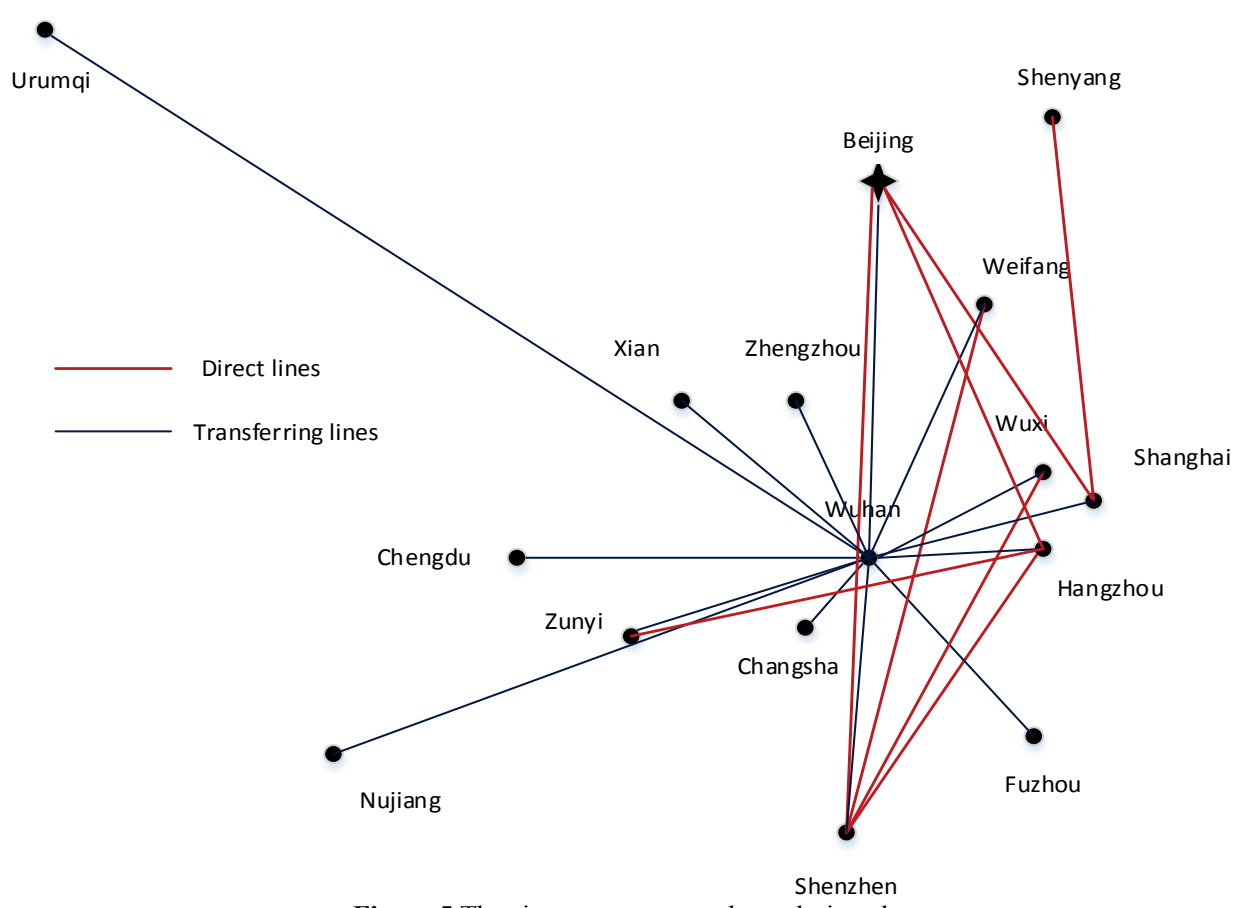

Figure 5 The air transport network we designed

\section{Conclusions}

We have presented an evidential reasoning-based approach for the design of an airline network for transporting express freight. In the proposed scheme, the selection of the transfer hub is a key point, and indices were considered in the design process, including cost, time, and the conditions of the airports. The proposed approach achieves network design by using a hierarchical evidential reasoning process, which is fast and flexible in dealing with heterogeneous data. A case study on the design of a transport network for the Shunfeng Company proved that Wuhang airport is the best choice as a transfer airport, and the results demonstrated that the proposed method had good convergence and that the final evaluation result had good discrimination. Future work may include the design of efficient optimization models to determine the best designs, considering cost, efficiency, and the conditions of the ports.

\section{References}

[1] Bing, Liu; Chengyao, Deng; Jieliang, Lin; Pan, Huang. Products Developing Department, CSR Meishan Co., Ltd. Discussion on development countermeasures of railway express freight transport equipments. // Railway Freight Transport. 4(2014).
[2] Rezaei, J.; Hemmes, A.; Tavasszy, L. Multi-criteria decision-making for complex bundling configurations in surface transportation of air freight. // Journal of Air Transport Management. 61, (2017), pp. 95-105. https://doi.org/10.1016/j.jairtraman.2016.02.006

[3] Si, Ma; Tiesen, Zeng; Yan, Chu. Comprehensive optimization model of diagrams of high-speed railway express freight trains operated in passenger train patterns. // System Planning, Supply Chain Management, and Safety, 2014 International Conference of Logistics Engineering and Management, 2014, pp. 327-334.

[4] Sebastian, H. J. Optimization Approaches in the Strategic and Tactical Planning of Networks for Letter, Parcel and Freight Mail. // Springer Berlin Heidelberg. 42, (2012), pp. 36-61. https://doi.org/10.1007/978-3-642-27612-5_3

[5] Yuzhao, Zhang; Yusong, Yan. An operation optimization for express freight trains based on shipper demands. // Discrete Dynamics in Nature and Society. 2014, 2(2014), pp. 1-8.

[6] Junqing, Shi; Xiaoning, Zhu; Whenhua, Gu. Route optimization of container multimodal transport based on non-stop express transportation. // Logistics: The Emerging Frontiers of Transportation and Development in China, 2008, pp. 3129-3134.

[7] Zhang, M. W.; Guo, S. T.; Li, T. The express aviation network hub optimization method research based on the genetic algorithm. // IEEE International Conference on Industrial Engineering and Engineering Management, 2011, pp. 860-864. https://doi.org/10.1109/ICIEEM.2011.6035294 
[8] Samora, I.; Franca, M. J.; Schleiss, A. J.; Ramos, H. M. Simulated annealing in optimization of energy production in a water supply network. // Water Resources Management. 30, 4(2016), pp. 1533-1547. https://doi.org/10.1007/s11269-016-1238-5

[9] Ennaceur, A.; Elouedi, Z.; Lefevre, E. Belief AHP method AHP method with the belief function framework. // International Journal of Information Technology Decision Making. 15, 3(2016), pp. 553-573. https://doi.org/10.1142/S0219622016500139

[10] Zhaoyang, Qu; Yaying, Li; Peng, Li. A network security situation evaluation method based on D-S evidence theory. // In Environmental Science and Information Application Technology (ESIAT), 2010 International Conference. 2010, pp. 496-499.

[11] Haiyan, Zhao; Xiao, Zhou; Xuebing, Liao; Linhao, Huang; Zhengxi, Xie. Performance evaluation of communication countermeasure system based on ds evidence theory and multi-aggregation model. // Robotics and Applications (ISRA), 2012 IEEE Symposium on, 2012, pp. 200-203.

[12] Vaidya, O. S.; Kumar, S. Analytic hierarchy process: An overview of applications. // European Journal of Operational Research. 169, 1(2006), pp. 1-29. https://doi.org/10.1016/j.ejor.2004.04.028

[13] Behzadian, M.; Khanmohammadi Otaghsara, S.; Yazdani, M.; Ignatius, J. A state-of the-art survey of topsis applications. // Expert Systems with Applications. 39, 17(2012), pp. 13051-13069. https://doi.org/10.1016/j.eswa.2012.05.056

[14] Dempster, A. P. Upper and lower probabilities induced by a multivalued mapping. // Annals of Mathematical Statistics. 38, 2(1967), pp. 325-339. https://doi.org/10.1214/aoms/1177698950

[15] Shafer, G. A mathematical theory of evidence. // Technometrics. 20, 1(1978), pp. 106. https://doi.org/10.1080/00401706.1978.10489628

[16] Xiaoyan, Su; Sankaran, Mahadevan; Peida, Xu; Deng, Yong. Dependence assessment in human reliability analysis using evidence theory and AHP. // Risk Analysis. 35, 7(2015), pp. 1296-1316. https://doi.org/10.1111/risa.12347

[17] Saaty, T. L. How to make a decision: The analytic hierarchy process. // European Journal of Operational Research. 48, 1(1990), pp. 9-26. https://doi.org/10.1016/0377-2217(90)90057-I

[18] Wenyu, Zhang; Zhenjiang, Zhang. Belief function based decision fusion for decentralized target classification in wireless sensor networks. // Sensors. 15, 8(2015), pp. 20524-20540. https://doi.org/10.3390/s150820524

[19] Zhenjiang, Zhang; Wenyu, Zhang; Han-Chieh, Chao; Chin, Feng Lai. Toward belief function based cooperative sensing for interference resistant industrial wireless sensor networks. // IEEE Transactions on Industrial Informatics. (2016), pp. 1-1.

\section{Authors' addresses}

\section{Fei Gao, PhD}

Institution School of Economics and Management,

Beijing Jiaotong University

Siyuan East Building, Haidian District, Beijing, 100044, China

E-mail: 13113145@bjtu.edu.cn

\section{Qilan Zhao, professor}

Institution School of Economics and Management,

Beijing Jiaotong University

Siyuan East Building, Haidian District, Beijing, 100044, China

E-mail: zhaoqilan@126.com 